\title{
GIS Based Fuzzy Logic Approach for Identification of Groundwater Artificial Recharge Site
}

\author{
Mostafa Moradi Dashtpagerdi ${ }^{1^{*}}$, Hassan Vagharfard ${ }^{2}$, Afshin Honarbakhsh $^{3}$, A. Khoorani ${ }^{2}$ \\ ${ }^{1}$ Graduated Watershed Management, Organization of Natural Resources and Watershed Management, \\ Karoon Watershed Management Office (KWMO), Shahrekord, Iran \\ ${ }^{2}$ Faculty of Natural Resources, Hormozgan University, Bandarabbas, Iran \\ ${ }^{3}$ Faculty of Natural Resources and Earth Sciences, University of ShahreKord, ShahreKord, Iran \\ Email: *Moradi2763@yahoo.com
}

Received May 21, 2013; revised June 20, 2013; accepted June 28, 2013

Copyright (C) 2013 Mostafa Moradi Dashtpagerdi et al. This is an open access article distributed under the Creative Commons Attribution License, which permits unrestricted use, distribution, and reproduction in any medium, provided the original work is properly cited.

\begin{abstract}
In recent decades population increasing and development of agriculture and also being mountainous and climatic characteristics of Sefieddasht plain and also nonuniform distribution of rainfall in study area have led to irregular use of groundwater resources in study area. This issue has led to critical condition of groundwater resources in Sefieddasht plain. This research was carried out to determine the suitable areas for artificial recharge in Sefieddasht plain. Four factors namely, alluvial quality, alluvial thickness, slope, and infiltration rate parameters were explored and maps produced and classified using GIS. Fuzzy logic model was used to determine the suitable areas for artificial recharge. Finally land use maps were used as a filter. Based on results $4.12 \%$ of region was recognized as suitable area for artificial recharge.
\end{abstract}

Keywords: Feasibility; Artificial Recharge; Sefieddasht Plain; Fuzzy Logic

\section{Introduction}

Water is indispensable for any life system to exist on earth and is a very important component for the development of any society [1]. A growing population and changing dietary trends mean a steeply rising water demand [2]. Demand for the worlds increasingly scarce water supply, is rising rapidly, challenging its availability for food production and putting global food security at risk, even as demand for water by all users grows, groundwater is being depleted [3]. Groundwater as a source of water supply has great advantages over surface water from streams, rivers, or lakes [4] and with increasing demands for water, ground resources are gaining much attention [5]. Due to climatic condition, a large portion of Iran is considered as arid and semiarid areas [6], More than $50 \%$ of precipitations take place in winters while less than $15 \%$ occur in summers. Thus, most of the rivers are dry in the mid springs until mid-fall range. Underground water substitutes the water shortage. Overuse of underground water resources decreases the ground water level in many aquifers. According to recent studies on water resource development in Iran, the total

\footnotetext{
"Corresponding author.
}

amount of annual precipitation is about 430 billion $\mathrm{m}^{3}$, of which about $20 \%$ is lost in the form of flash floods to the playas and seas [7]. It is therefore important to augment the groundwater resource by artificial recharge, using floodwaters [8]. Many studies have used GIS for locating most suitable sites for artificial recharge. For example, Nirmala et al. (2011) used GIS to study artificial recharge of groundwater in Sathyamangalam and Melur villages, Chennai [8]. Balachandar et al. (2010), and Ravi Shankar \& Mohan (2005) used GIS for identification of site-specific artificial-recharge techniques in different parts of India. Ghayomian et al. (2007) applied Fuzzy Logic among GIS techniques to determine most suitable areas for artificial groundwater recharge in a coastal aquifer in Gavbandi Drainage Basin [9]. Also Nouri et al. (2005) have had the same studies using GIS techniques and used Fuzzy to carry out their study [10]. Sefiddasht plain has been located in west of Iran country. Unfortunately, the groundwater condition in this plain is critical and its balance is negative. So, artificial recharge of groundwater will be helpful to control floods and also to rising water table in this plain. Hence this study was performed with the purpose of locating most suitable sites for artificial recharge in Sefiddasht plain using fuzzy Logic. 


\section{Materials and Methods}

\subsection{Study Area}

Sefiddasht plain is located in Chaharmahal va Bakhtiyari province in Iran Coordinates of Sefiddasht plain (center of plain) in UTM coordinate system are X = 513,205 and $\mathrm{Y}=3,562,547$. Its altitude is $2150 \mathrm{~m}$ from sea level. Area of this plain is $201 \mathrm{~km}^{2}$. Due to irregular use of groundwater resources in Sefiddasht plain, this plain is now barred. Figure 1 shows Study area and its position in Iran country (Figure 1).

\subsection{Thematic Layers}

Among effective factors in locating suitable areas for artificial recharge slop, alluvial thickness, infiltration rate, Electrical Conductivity (EC) and Landuse factors were selected and examined [11]. Among these, slop, alluvial thickness, infiltration rate, Electrical Conductivity (EC) factors were used as principle factors and land use were used as a filter. So maps based on these factors were prepared using GIS software and then Fuzzy Logic was used to overlay these layers.

\subsection{Fuzzy Logic Model}

In the classical setting an element either belongs to a set

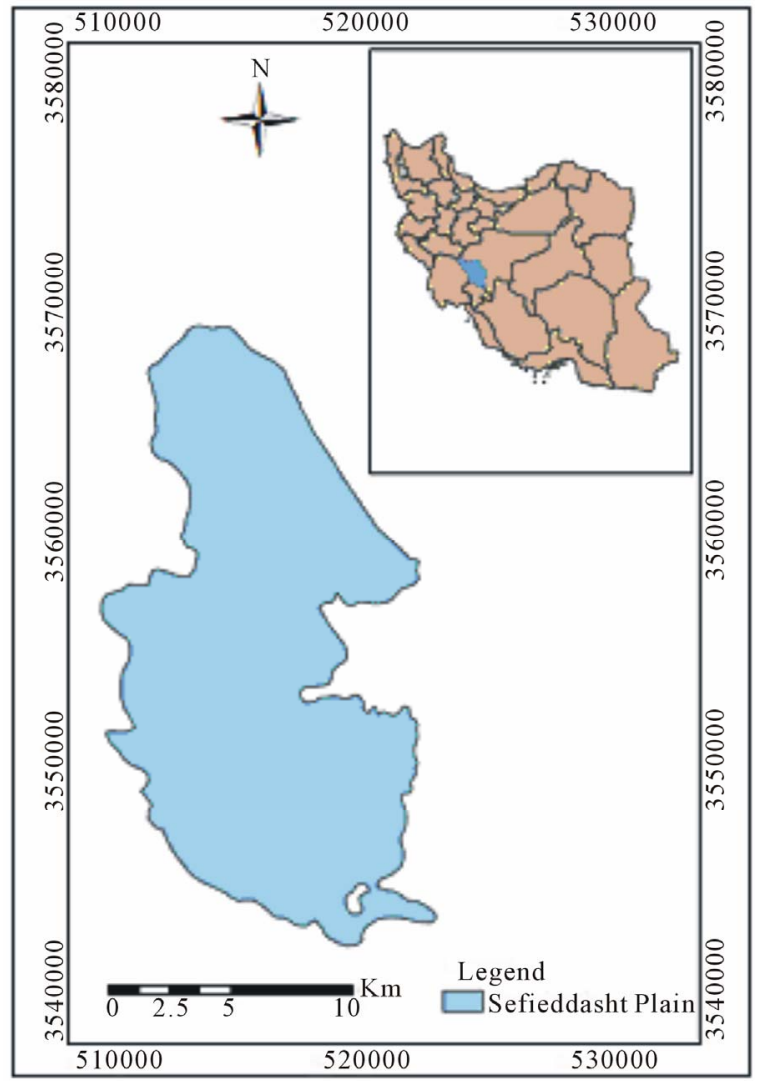

Figure 1. Study area and its position in Iran country. or not. If $A$ is a classical set then the formula $x \in A$ is either absolutely true or absolutely false. In the case of a fuzzy set $A$, an element $x$ can attain more than two degrees of its membership. Thus the formula $x \in A$ may be only partially satisfied [11]. Since then, fuzzy subsets have been applied to diverse field [12] In contrast to Boolean logic, no certainty exists in fuzzy logic. Therefore, no unit area is definitely satisfactory or unsatisfactory for artificial recharge. Given two or more maps with fuzzy membership functions for the same set, a variety of operations can be employed to combine the membership values together [9]. Zimmermann and Zysno (1980) discuss a variety of combination rules [13]. An et al. (1991) discuss five operators that were found to be useful for combining exploration datasets, namely the fuzzy AND, fuzzy OR, fuzzy algebraic product, fuzzy algebraic sum and fuzzy gamma operator. Fuzzy algebraic product is defined as [14]:

$$
u_{\text {Combination }}=\prod_{i=1}^{n} u_{i}
$$

where $u_{i}$ is the fuzzy membership values of $i^{\text {th }}$ map and $i=1,2,3, \cdots, n$. In fuzzy algebraic product operator as a t-norm, the weight of compositional layer in the multilayer intersection section is equal to their products and for other sections is zero. Therefore mentioned operator has a decrease effect [15]. Although the fuzzy algebraic product gives an output that is decreasive in nature, it does utilise every membership value to produce the result, unlike the fuzzy minimum [16]. Table 1 shows membership functions for different classes of used parametrs in Fuzzy logic.

\section{Results and Discussion}

Ordinary Kriging Geostatistical method has been used to preparing alluvial thickness and alluvial quality maps in this research.

Classes of alluvial thickness, infiltration rate, electrical conductivity and slope have been shown in Tables $\mathbf{2 - 5}$, respectively.

Topographic maps of the Sefiddasht plain at the scale 1:25,000 were used to develop a slope map using Digital Elevation Model (DEM). On the slope map [17,18], slopes are classified into four classes (Table 5).

Using Fuzzy logic model to overlay thematic layers, map of most suitable areas for artificial recharge was developed (Figure 2).

Also Table 6 shows suitable and unsuitable areas of artificial recharge in sefiddasht plain based on Fuzzy logic model.

Comparing Table 5 can be observed that suitable areas for artificial recharge in fuzzy logic are 9.97 percent. According to different types of land-use, only rangelands are appropriate for artificial recharge. Therefore, range- 


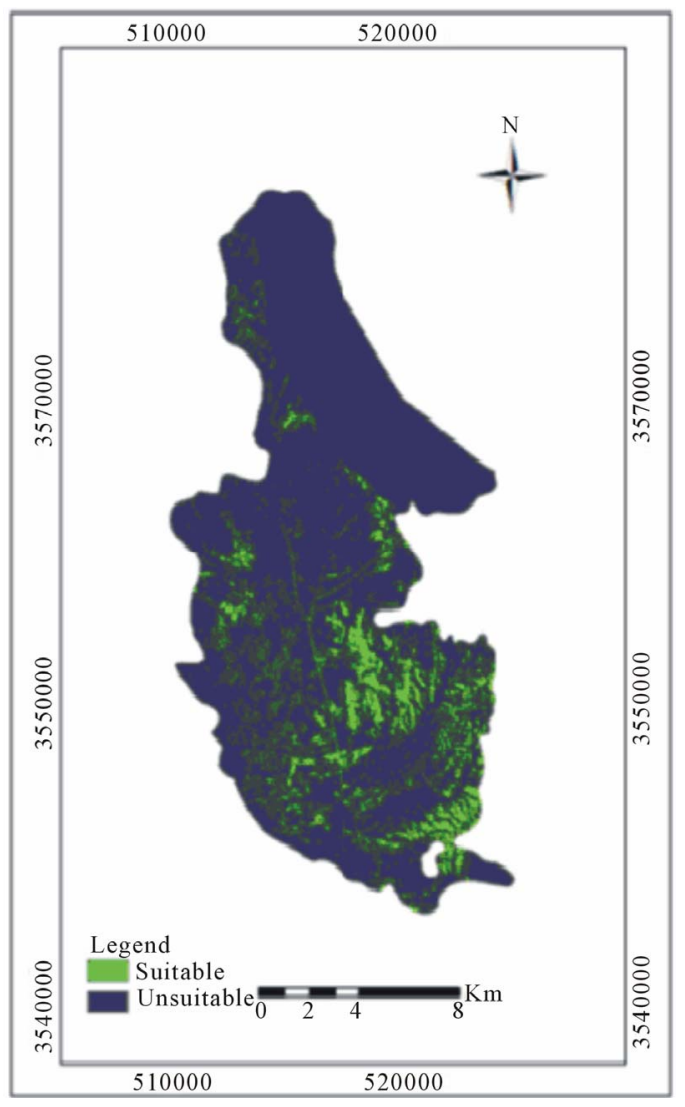

Figure 2. Suitable Areas for artificial recharge in Sefieddasht based on Fuzzy model.

Table 1. Membership functions for thematic layers in fuzzy logic.

\begin{tabular}{|c|c|c|}
\hline Thematic layer & Classes & Membership \\
\hline \multirow{4}{*}{ Slope (\%) } & $0-2$ & 0.7 \\
\hline & $2-4$ & 0.5 \\
\hline & $4-8$ & 0.3 \\
\hline & More than 8 & 0.01 \\
\hline \multirow{4}{*}{$\begin{array}{l}\text { Infiltration rate } \\
\quad(\mathrm{mm} / \mathrm{hr})\end{array}$} & $0-15$ & 0.01 \\
\hline & $15-25$ & 0.34 \\
\hline & $25-45$ & 0.74 \\
\hline & More than 45 & 0.95 \\
\hline \multirow{4}{*}{$\begin{array}{l}\text { Dry alluvial } \\
\text { thickness (m) }\end{array}$} & $0-10$ & 0.01 \\
\hline & $10-20$ & 0.5 \\
\hline & $20-30$ & 0.65 \\
\hline & More than 30 & 0.8 \\
\hline \multirow{4}{*}{$\begin{array}{c}\text { Electrical } \\
\text { conductivity } \\
\text { (lmhos/cm) }\end{array}$} & $0-1000$ & 0.6 \\
\hline & $1000-2250$ & 0.45 \\
\hline & $2250-4000$ & 0.25 \\
\hline & More than 4000 & 0.01 \\
\hline
\end{tabular}

Table 2. Alluvial thickness (m) in Sefieddasht plain.

\begin{tabular}{cccc}
\hline VALUE & Classes & Area $\left(\mathrm{km}^{2}\right)$ & Area (\%) \\
\hline 1 & $20-30$ & 4.2 & 2.09 \\
2 & $30-45$ & 26.5 & 13.17 \\
3 & $>45$ & 170.3 & 84.73 \\
\hline
\end{tabular}

Table 3. Infiltration rate $(\mathrm{mm} / \mathrm{hr})$ in Sefieddasht plain.

\begin{tabular}{ccc}
\hline Classes & Area $\left(\mathrm{km}^{2}\right)$ & Area (\%) \\
\hline $0-15$ & 67.315 & 33.49 \\
$15-25$ & 67.395 & 33.53 \\
$25-45$ & 16.6 & 8.27 \\
$>45$ & 49.62 & 24.69 \\
\hline
\end{tabular}

Table 4. EC ( $\mu \mathrm{mhos} / \mathrm{cm})$ in Sefieddasht plain.

\begin{tabular}{ccc}
\hline Classes & Area $\left(\mathrm{km}^{2}\right)$ & Area (\%) \\
\hline $0-500$ & 9.828 & 4.89 \\
$500-1000$ & 188.21 & 93.64 \\
$>1000$ & 2.93 & 1.458 \\
\hline
\end{tabular}

Table 5. Classification of slope in Sefiddasht plain.

\begin{tabular}{ccc}
\hline Value & Area $\left(\mathrm{km}^{2}\right)$ & Area (\%) \\
\hline $0-2$ & 31.05 & 15.45 \\
$2-4$ & 52.66 & 26.20 \\
$4-6$ & 52.01 & 25.88 \\
$6-8$ & 62.22 & 32.45 \\
\hline
\end{tabular}

Table 6. Areas of suitable and unsuitable sites for artificial recharge based on fuzzy logic.

\begin{tabular}{ccc}
\hline Value & Area $\left(\mathrm{km}^{2}\right)$ & Area $(\%)$ \\
\hline Unsuitable & 180.96 & 90.03 \\
Suitable & 20.01 & 9.96 \\
\hline
\end{tabular}

lands and non-rangelands regions are distinguished on the land-use map and coded as one and zero, respectively. This classification is applied to the map of suitable areas for artificial recharge, as a filter (Table 7).

Based on Table 6, 55.3\% of Sefiddasht plain is rangeland that its area is equal to $111.15 \mathrm{Km}^{2}$. Table 8 shows suitable and unsuitable areas of artificial recharge using land use filtering.

Suitable and unsuitable areas of artificial recharge based on Fuzzy model using land use filtering shows in Tables $\mathbf{6}$ and 8 . It can be said that using land use map as a filter, suitable areas for artificial recharge have de- 
Table 7. Land use in Sefieddasht.

\begin{tabular}{ccc}
\hline Land use & Area $\left(\mathrm{km}^{2}\right)$ & Area (\%) \\
\hline Rangeland & 111.15 & 55.3 \\
Agri & 88.51 & 44.038 \\
Lake & 1.32 & 0.658 \\
Sum & 201 & 100 \\
\hline
\end{tabular}

Table 8. Areas of suitable and unsuitable sites for artificial recharge based on Fuzzy logic using land use filtering.

\begin{tabular}{ccc}
\hline VALUE & Area $\left(\mathrm{km}^{2}\right)$ & Area (\%) \\
\hline Unsuitable & 192.71 & 95.88 \\
Suitable & 8.28 & 4.12 \\
\hline
\end{tabular}

creased. Table 7 shows that $4.12 \%$ of area is suitable area of artificial recharge in Fuzzy Model using land use filtering.

\section{Conclusion}

Groundwater resources provide the most important amount of water resources, and many agricultural units have been subjected to negative balance of water due to overharvesting of wells $[19,20]$. Hence proper management of groundwater resources is necessary and artificial recharge of groundwater can be helpful in management of groundwater and increasing the groundwater table. One of the most important factors in successful recharge of groundwater resources is locating suitable areas for these projects. Therefore, site selection of artificial recharge suitable areas is very important. Four factors namely, alluvial quality, alluvial thickness, slope, and infiltration rate parameters were explored, classified, weighted and overlaid using GIS system. To overlay these layers, fuzzy logic was used and the study areas were divided into two suitable and unsuitable classes for artificial recharge. Results showed that based on overlay Fuzzy logic $4.12 \%$ of study area was suitable for artificial recharge. In this matter it can be said that suitable areas have been decreased from 9.96 percent to 4.12 percent using land use filtering. In fact, land use is one of the major factors of water resources management restriction.

\section{REFERENCES}

[1] V. B. M. Sayana, E. Arunbabu, L. Mahesh Kumar, S. Ravichandran and K. Karunakaran, "Groundwater Responses to Artificial Recharge of Rainwater in Chennai, India: A Case Study in an Educational Institution Campus," Indian Journal of Science and Technology, Vol. 3, No. 2, 2010, pp. 124-130.
[2] G. Berndes, "Water Demand for Global Bioenergy Production: Trends, Risks and Opportunities,” Wissenschaftlicher Beirat Der Bundesregierung Globale Umweltveränderungen (WBGU), 2008.

[3] M. W. Rosegrant, X. Cai and S. A. Cline, "Global Water Outlook to 2025, Averting an Impending Crisis,” International Water Management Institute (IWMI), 2002.

[4] E. H. Hofkes and J. T. Visscher, "Artificial Groundwater Recharge for Water Supply of Medium-Size Communities in Developing Countries,” International Reference Center for Community Water Supply and Sanitation, Hague, 1986.

[5] M. M. Kheirkhah Zarkesh, A. M. J. Meijerink and M. Goodarzi, "Decision Support System (DSS) for Site Selection Floodwater Spreading Schemes Using Remote Sensing (RS) and Geographical Information Systems (GIS), DESERT 12, 2008, pp. 149-164.

[6] K. Mehrvarz and A. Kalantari, "Investigation of Quarternary Deposits Suitable for Floodwater Spreading,” International Congress on River Basin management, 2007.

[7] A. A. Alesheikh, M. J. Soltani, N. Nouri and M. Khalilzadeh, "Land Assessment for Artificial Recharge Site Selection Using Geospatial Information System," International Journal of Environmental Science and Technology, Vol. 5, No. 4, 2008, pp. 455-462.

[8] R. Nirmala, M. Shankara and D. Nagaraju, “Artificial Groundwater Recharge Studies in Sathyamangalam and Melur Villages of Kulathur Taluk, Pudukottai District, Chennai, Using GIS Techniques,” International Journal of Environmental Sciences, Vol. 1, No. 7, 2011, p. 1592 1608.

[9] J. Ghayoumian, M. Mohseni Saravi, S. Feiznia, B. Nouri and A. Malekian, "Application of GIS Techniques to Determine Areas Most Suitable for Artificial Groundwater Recharge in a Coastal Aquifer in Southern Iran,” Journal of Asian Earth Science, Vol. 30, No. 2, 2007, pp. 364-347. http://dx.doi.org/10.1016/j.jseaes.2006.11.002

[10] B. Nouri, J. Ghayoumian, M. Mohseni Saravi, A. Darvish Sefat and S. Feiznia, "Identification of Suitable Sites for Groundwater Artificial Recharge by Basins Method Using GIS,” Iranian Journal. Natural Resources, Vol. 57, No. 3, 2005, pp. 635-647.

[11] ASCE Standard, Environmental and Water Resources Institute, American Society of Civil Engineers. Standard Guidelines for Artificial Recharge of Groundwater, ASCE Standards, EWRI/ASCE 34-01, 2001, p. 106.

[12] R. Horcık, “Algebraic Properties of Fuzzy Logic,” Ph.D Thesis, Czech Technical University in Prague, 2005.

[13] A. Kordi and A. Moussavi, "On Fuzzy of BCI-Algebras," PUMA, Vol. 18, No. 3-4, 2006, pp. 301-310.

[14] H. J. Zimmermann and P. Zysno, "Fuzzy Set Theory and Its Application,” Kluwer-Nijhoff Publishing, Boston, Dordrecht, Lancaster, 1980, 363 p.

[15] P. An, W. M. Moon and A. Rencz, “Application of Fuzzy Set Theory for Integration of Geological, Geophysical and Remote Sensing Data," Canadian Journal of Exploration Geophysics, Vol. 27, No. 1, 1991, pp. 1-11.

[16] M. Karimi, M. B. Menhaj and M. S. Mesgari, "Preparing 
Mineral Potential Map Using Fuzzy Logic in GIS Environment," The International Archives of the Photogrammetry, Remote Sensing and Spatial Information Sciences. Vol. XXXVII. Part B8, Beijing, 2008.

[17] J. Ghayoumian, B. Ghermezcheshme, S. Feiznia and A. A. Noroozi, "Integrating GIS and DSS for Identification of Suitable Areas for Artificial Recharge, Case Study Meimeh Basin, Isfahan, Iran,” Environmental Geology, Vol. 17, No. 4, 2005, pp. 493-500. http://dx.doi.org/10.1007/s00254-004-1169-y

[18] A. C. Saraf, "Integrated Remote Sensing and GIS for Groundwater Exploration and Identification of Artificial Recharge Sites,” International Journal of Remote Sensing, Vol. 19, No. 10, 1998, pp. 2595-2616. http://dx.doi.org/10.1080/014311698215018

[19] H. Ahani, M. Kherad, M. R. Kousari, , M. RezaeianZadeh, M. A. Karampour, F. Ejraee and S. Kamali, "An Investigation of Trends in Precipitation Volume for the Last Three Decades in Different Regions of Fars Province, Iran,” Theoretical and Applied Climatology, Vol. 109, No. 3-4, 2012, pp. 361-382. http://dx.doi.org/10.1007/s00704-011-0572-z

[20] M. Moradi, H. Vagharfard, A. Khorani and V. Mahmoodinejad, "Interpolation Methods in Evaluation of Groundwater Salinity Zonation Using Cross-Validation Technique Case Study: Lowland Shahrekord,” Iranian Remote Sensing \& GIS Journal, Vol. 3, No. 1, 2011, pp. 34-44. 